\section{New international dental ambassadors metuvark established}

The Royal College of Surgeons of Edinburgh (RCSEd) held its inaugural Dental Ambassadors Conference on Friday 4 October 2019. Thirty-five UK and International Ambassadors met at the College to develop networks to drive the advancement of dental care worldwide by supporting the development of the whole dental team.

The unique UK Ambassador network has three defined roles to

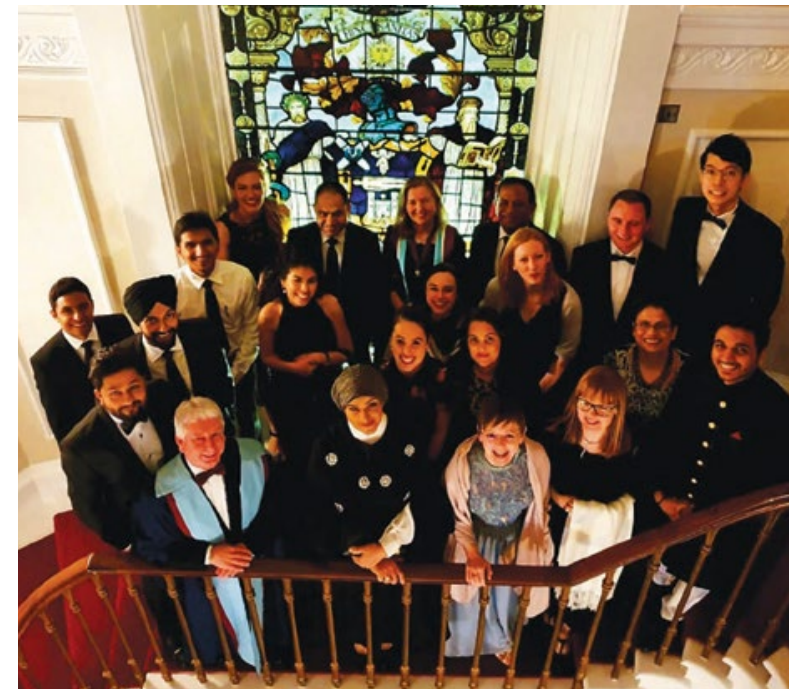
support the whole dental team at every stage of their careers: Early Career, Dental Team and Dental Specialty Ambassadors. In addition, there are International Ambassadors from 16 countries who will work in regional networks covering North Africa and the Mediterranean, the Middle East and South East Asia. This worldwide network was established to represent the dental community, shape and influence the direction of dental care provision and build supportive networks both in the UK and Internationally.

Dental Ambassador Lead and Vice Dean of the Faculty of Dental Surgery, Professor Helen Craddock, said: 'The Faculty of Dental Surgery is delighted to launch this international network of outstanding individuals who will give direction and support to the development of dental professionals.

'Their remit is to inspire, support, inform and share best practice within the dental environment in their region, leading to a more highly skilled dental workforce, better able to meet the needs of their respective populations.

'This has been an amazingly productive conference, with dentists and dental care professionals from as far as South East Asia coming together to share their ideas and enthusiasm for developing the dental workforce for the benefit of patient care.'

\section{BADN RESPONDS TO REDUCTION IN ARF}

The British Association of Dental Nurses (BADN) has welcomed the very slight reduction by the General Dental Council (GDC) in the Annual Retention Fee (ARF) for dental nurses of $£ 2$ per year, for the next three years.

However, BADN still strongly believes that $£ 114$ per year is an excessive amount for dental nurses - many of them earning only minimum wage and often only working part time particularly in view of the fact that the majority also have to pay for their own indemnity cover, and their CPD costs (which are still not tax-allowable for employees). BADN continues to urge the GDC to lower further the ARF for dental nurses, the lowest paid members of the dental team, instead of banding them with hygienists and therapists, who receive much higher salaries; and to consider a lower rate for all registrants who work part-time.

BADN also urges the GDC, and other dental associations, to lobby HMRC for tax relief on CPD costs for all members of the dental team. The ARF for dentists has also been reduced, from $£ 890$ to $£ 680$ a year.

\title{
CDO VISITS AWARD WINNING TRAINING PRACTICE
}

Chief Dental Officer (CDO) Sara Hurley visited Crook Log Dental Practice in Bexleyheath to congratulate them on their award winning training facilities.

Principal dentists Baber Khan and Semina Younis were honoured to welcome the $\mathrm{CDO}$ to their practice and introduce their team.

Sara was shown around the practice and given a small presentation on how the Foundation Training practice has improved over the years, producing award winning Foundation dentists.

Dr Baber Khan, Foundation Trainer, said:

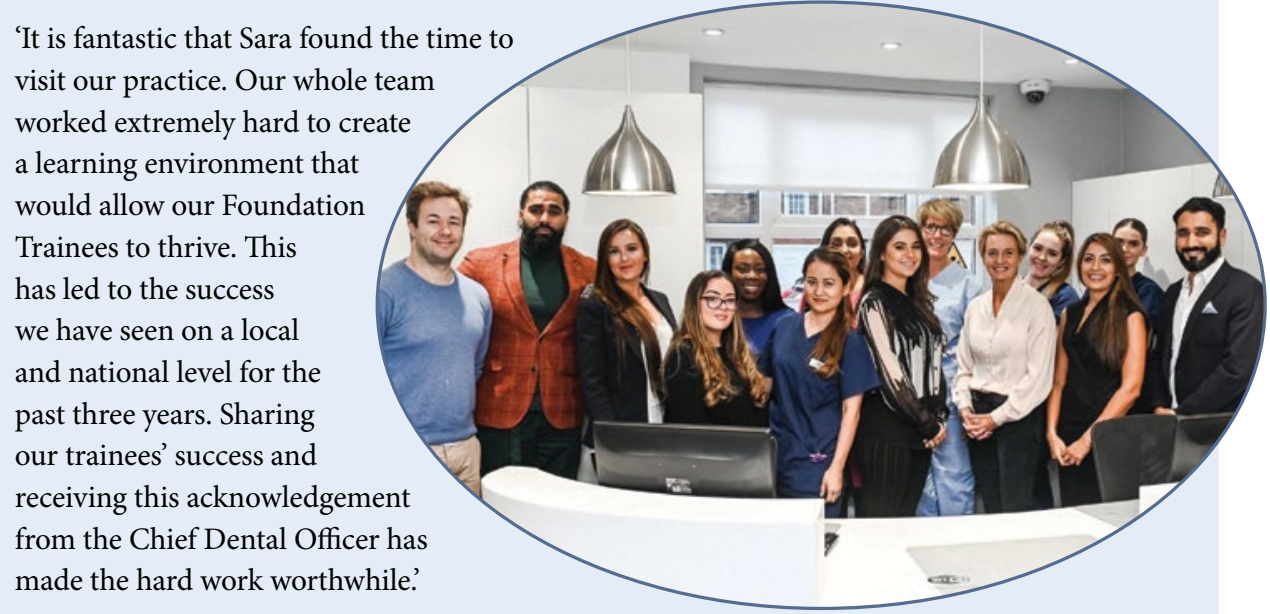

